\title{
ICT as an Enabler to Academic Success of Students with Visually Impaired at Sim University: Hermeneutics Approach
}

\author{
Francis Simui ${ }^{1}$, Sophie Kasonde-Ngandu ${ }^{2}$ \\ Institute of Distance Education ${ }^{1}$, Department of Educational \\ Psychology, Sociology and Special Education ${ }^{2}$. \\ University of Zambia \\ Lusaka, Zambia \\ simuifrancis@gmail.com ${ }^{1}$, sophiekasonde@yahoo.com²
}

\author{
Leonorah T. Nyaruwata \\ Zimbabwe Open University \\ Harare, Zimbabwe \\ lnyaruwata4@gmail.com
}

\begin{abstract}
While the World Health Organisation's (WHO) benchmark is 15.6 percent, 'Sim' (pseudonym) University is way below that benchmark as only 0.001 percent are students classified as 'disabled' despite being in existence for more than $\mathbf{5 0}$ year. Within the 0.001 , students with visually impaired (SwVI) are the majority estimated at 70 percent. In the 21 st century, ICTs generally serve as catalysts to academic success of students in Universities. Therefore, the purpose of this study was to explore the role played by Information Communication Technologies (ICTs) as enablers to academic success of SwVI at Sim University. A Hermeneutic Phenomenology approach guided the research process. Seven participants volunteered to voice their lived experiences and a cluster of themes on ICT usage emerged subsequently. Emerging from the lived academic experiences of SwVI is a host of self-initiated ICTs in use namely: ordinary typewriters, voice recorders, scanners, jaws and computers meant to facilitate learning amidst a negatively charged learning environment. In conclusion, if ICTs are to serve as effective assistive learning devises, ICTs developers and ICT policy makers should consider SwVI not just as ICTs consumers but equal innovators who must be consulted to transform the education landscape at tertiary level.
\end{abstract}

Visual Impairment, ICT, Hermeneutics Phenomenology, Higher Education (key words)

\section{INTRODUCTION}

This paper is an extract from the lead researcher's doctoral thesis on lived experiences of Students with Visual Impairments (SwVI) while pursuing their studies at 'Sim' University (Pseudonym) in Sub-Saharan Africa. In using the Hermeneutic approach, the researchers accept the difficulty of bracketing, as advanced through the Transcendental Phenomenology of Edmund Husserl (1859-1938). Instead, the study leans on the works of Martin Heidegger (1889-1976) dubbed, Hermeneutic Phenomenological. This departure is primarily because of the rejection of the idea of suspending personal opinions and the turn for the interpretive narration to the description, as advanced by numerous philosophers such as including Martin Heidegger, Maurice Merleau-Ponty, JeanPaul Sartre, Emmanuel Lévinas, Jean-Luc Nancy, and JeanLuc Marion (Healy, 2012). Therefore, this study attempts to unveil the world as experienced by the SwVI through their life world stories.

\section{BACKGROUND}

The World Report on Disability observes that about a billion people, including children, (approximately 15.6 percent) of the world's population live with some form of disability (WHO, 2011). The report notes the disproportional effects which disability has on people and children in particular, from lower income countries and those living in the poorest wealth quintile of the world's population. Many children with disabilities in these circumstances are excluded from education. They remain most negatively marginalized and excluded from education. They continue to experience dismissive attitudes, discrimination, and are largely invisible in official statistics used for education planning and programme implementation. Such discrimination and exclusion has a negative effect on their livelihoods (UNICEF, 2013). UNESCO (2014) further confirms this prevailing situation. UNESCO argues that, worldwide, there are still about 57 million children of primary school age, who are not in school due to financial, social or physical challenges. More than half of the 57 million children out of school are in Sub-Saharan Africa.

\section{LITERATURE REVIEW}

\section{A. Prevalence of learners with disability at tertiary level,} developed countries 
In developed countries such as United States of America and Canada, persons with reported disabilities represented a small segment of the general population at postsecondary education level, averaging between $1.5 \%$ and $11 \%$ across North America (Harrison and Wolforth, 2012; MacKean, 2011 and Fichten, et al., 2003). Innovations in learning and assistive technologies, as well as provisions in disabilities supports, were viewed as central factors contributing to the increase in enrolment and graduation rates from colleges for individuals with disabilities (Harrison and Wolforth, 2012; Klemes, et al., 2006; MacKean, 2011).

\section{B. Experiences of Learners with disabilities in learning institutions}

At present, a number of studies on the education of learners with disabilities in higher education have been conducted including Polushin's (2015), focused on the Inclusive Andragogy in Distance Education using a Phenomenological Approach at a Canadian tertiary institution. Findings suggest inclusive andragogy needed a systemic approach to address learner and cultural variability. Specifically, systemic, curricular, technological and social accessibility supported by awareness training and interdisciplinary team knowledge and collaboration emerged as essential themes of the participants' lived experiences.

Lourens, (2015), in his thesis, focused on the 'lived experiences of higher education for students with a visual impairment. The study findings described the challenges related to the learning environment, the participants were sometimes confronted with unwilling lecturers, a lack of communication amongst important role-players, late course material and/or headaches and muscle tension from the effort of reading with limited sight (Lourens, (2015).

In addition, Grönlund, Lim and Larsson (2010), observed that in developing countries there existed many obstacles in the process of implementing inclusive education. In particular, Grönlund, Lim and Larsson (2010) focused on effective use of Assistive Technologies for Inclusive Education in developing Countries. In conducting this study, an in-depth case study of two developing countries, Bangladesh and Tanzania were reviewed. The findings showed that since Assistive Technologies were only part of the equation for a country to achieve inclusive education, a high-level national perspective was required.

\section{METHODOLOGY}

The study applied Hermeneutic phenomenology. Hermeneutic phenomenology is concerned with human experience as it is lived. The focus is to illuminate particulars and seemingly trivial aspects within experience that may be taken for granted in our lives, with a goal of constructing meaning and achieving a sense of understanding (Langdridge, 2007). In addition, Langdridge (2007) argues that our experiences can be best understood through stories we tell of that experience. To understand the life world we need to explore the stories people tell of their experiences, often with the help of some specific hermeneutic (interpretation).

\section{Research Design}

A cross-sectional research design was applied to study the lived experiences of SwVI using Heideggerian Hermeneutics Phenomenology lenses. Heidegger's thesis is on 'Being and Time', as advanced by Martin Heidegger and further expanded by van Manen's four reflective thematic areas on lived experiences as follows: (i) lived space - Spatiality; (ii) lived body - Corporeality; (iii) lived time - Temporality; and (iv) lived human relation - Relationality (van Manen 2007).

\section{Sample Size \& Selection Criteria}

According to Neuman (2003), qualitative research works focus on non-probability or a non-random sample, which entails that they seldom determine the sample size in advance. To this effect, sample Size consisted of seven participants. In order to choose research participants purposively, an inclusion/exclusion criteria was developed adapted from van Manen (2007). To be included as a participant, each student needed to:

i). Lived with a visual impairment (Corporeality).

ii). Lived with a visual impairment for more than a year in the university (Temporality).

iii). Lived with the visual impairment in the target university (Spatiality)

iv). Lived with a visual impairment while studying with others in a university (Relationality)

v). Willing to participate in the study through three face-toface interviews.

\section{Research tools}

In this study, the researcher used the following research tools namely: un Structured Interviews schedule, Focused Group Discussions guide and observation guide. Use of multiple tools strengthened the validity and reliability of the study findings as evidence was collaborated and triangulated from different viewpoints.

\section{Data generation procedure}

Data generation procedure assumed a four steps approach as follows:

i). At step 1, Shadowing and Unstructured Interview techniques applied to be a PhD Student with Visual Impairment (SwVI).

ii). At step 2, two Undergraduate SwVI purposively engaged and interviewed separately. While one of the two participants happened to be the only SwVI under the distance-learning mode, the other one was in his fourth and final year at regular study mode.

iii). At Step 3, a team of 3 second-year non-visually impaired students were engaged to identify and interview three SwVI on their lived experiences within the university. This helped to widen the scope of the research data generators' perspectives.

iv). Step 4 involved 3 second year SwVI in a Focused Group Discussion composed of a female with albinism, a male student with low vision (SwLV) and a totally blind. These helped to comment on the various emerging themes. 


\section{Analysis and interpretation}

The analysis of data in this study was concurrently done throughout the data gathering process using Inductive Data Analysis. Field notes and interview transcriptions were reviewed from time to time to identify the emerging themes or patterns. The data were coded accordingly from the sources reviewed and across each site case. The data was analysed thematically and the identified themes were cross-checked by the participants for validation purposes in line with Clarke and Braun (2013).

\section{Trustworthiness}

In this study Guba's (1981) four criteria was applied. The four elements are: (i) credibility, (ii) transferability, (iii) dependability, and (iv) confirmability. Data generation process was triangulated using observation, focus groups and individual interviews. The researchers used reflexivity approach to decipher meaning from generated data. In addition, the researcher had early familiarity with the culture of participants prior to data generation. The data generation procedure and boundaries were documented for the purposes of ensuring transferability of the study findings to different settings. Further, given that the findings were presented verbatim coupled with participant checks on the research, the study meets the dependability and confirmability criteria as well.

\section{Ethical Considerations}

In carrying out this study, ethical issues as guided by Cohen $e t$ al. (2000), such as verbal and/or written consents from all participants were followed. Therefore, pseudonyms were assigned in place of actual names, to assure confidentiality and privacy. The pseudonym given were as follows: Tom, Joe, Steel, Charm, Brid, Tau and Frey. In addition, the name of the university where the participants were drawn from, a pseudonym 'Sim University' was assigned, to hide their identities.

\section{FINDINDS AND DISCUSSION}

\section{Participants' Profiles}

In view of ethical considerations, pseudonym were used to represent each participants for confidentiality and anonymity purposes. To understand the life world we need to explore the stories people tell of their experiences, often with the help of some specific hermeneutic (interpretation).

TABLE I. PARTICIPANTS' PROFILES

\begin{tabular}{|l|l|l|l|}
\hline Table Head & \multicolumn{3}{|c|}{ Table Column Head } \\
\hline [1] Tom & PhD candidate & 48 & Employed \\
\hline [2] Joe & B.Ed. Special & 27 & Unemployed \\
\hline [3]Charm & B.Ed. Special & 38 & Employed \\
\hline [4] Steel & B.Ed. Special & 36 & Employed \\
\hline [5] Frey & B.Ed. Special & 28 & Unemployed \\
\hline [6] Brid & B.Ed. Special & 25 & Unemployed \\
\hline [7] Tau & B.Ed. Special & 28 & Unemployed \\
\hline
\end{tabular}

\section{Emerged Themes}

After a six month period of interacting with SwVI, the major themes that emerged were: (i) negative attitudes; (ii) involvement in decision making process; (ii) innovativeness among SwVI through multiplicity of ICTs; (iv) Academic progression and success. What follows below is a detailed presentation of findings based on the four themes as guided by the research objectives.

\section{Involvement in decision making}

Involvement of SwVI in decision making by the university administrators played a pivotal role in developing innovative ways to deal with complex challenges. This enabler, though applied at a low scale, yielded groundbreaking-results. The example of Tom, whom the teaching staff, while pursuing his diploma, almost was excluded from school because of negative attitudes. It was only when, one member of staff [college counsellor], consulted Tom that a ground-breaking solution was found, using an typewriter meant for sighted to type all his assignments, tests and examinations, even when he could not see what he was typing.

... Others were even advocating that 'let him be expelled. Let him be sent home.' He is incompatible. The then late [...] happen to be the college counsellor, he advised, 'why don't we consult him and establish what else can be done. If all fails, then we can recommend a transfer to other colleges. So, that is how I was called.... He told me the resolutions of the staff meeting, that I was asked to leave due to challenges lecturers had understanding braille. He then asked me for my input. I said no, it will not make sense for me to go, because I am already here. [Counsellor] But, how do you communicate with your lecturers, because they need to mark your test and assignments? Then I remembered to say, if I can get a typewriter then I think this will easy the challenge at hand among my lecturers. [Counsellor] 'how can you use a typewriter when you cannot see what you will be typing?' [Tom], It will be better. As long as what I am typing is readable by the sighted. That's how the man said, OK! and then wrote letters to many organisations to request for a donation of a typewriter. One organisation called Lottery club responded and donated a triumph typewriter to me, (Tom 04.01.2017). 
It is clear that solutions to the challenges encountered in the process of implementing inclusive education lie with the excluded persons, if only they can be engaged and consulted in decision-making process, institutions are bound make a break-through to a multitude of equity challenges they face. In the case of Tom, a Typewriter became a solution to the problem of communication between a braille expert student and ordinary lecturers oriented to handle ordinary students alone. In this instance, the triumph typewriter was the triumph of not only Tom but also the college and society at large, as demonstrated by the collage Principal at a time Tom finally graduated with a merit. In the words of Tom:

...Eventually, I did very well. At the end of the year, I got a merit. In some courses, I did have some As [distinctions]. I even worn some prizes in some courses. At a time I was leaving [...], the principal called me and said, 'we are really humbled.' We never knew that blind people can make it here! Because, earlier, they had tried to enrol 3 blind persons. But, all of them failed to graduate. [Principal]With what you have done, kindly make some recommendations for us, so that we continue enrolling blind students. [Tom] Since I left the college, every year they have been enrolling blind students. This time around when I last visited the college, 2 weeks ago, to train them how to use jaws, they were telling me that they had almost ten (10) blind students. ...Although the challenge remains, the issue of communication, (Tom 04.01.2017).

The devised solution helped to change the mind-set of the administrators and lecturers alike. Stereotype was at play and should be discouraged at all times, when dealing with SwVI. Tom's success had a ripple effect so was failure of the first 3 entrants at [...] college, which resulted in stereotype of all blind students in the minds of staff. However, when Tom had a breakthrough, his success led to change of attitude among staff and many other blind students were attracted and enrolled yearly.

\section{Other Assistive Learning Devises in use}

Assistive Learning Devises (ALD) proved vital tools to the academic success of SwVI as described by Tom. 'I had to come with my old typewriter for all my academic work as first year student in the university.' The same could be said for Joe in the use of ALD for academic activities.

....In first year, it was a big challenge. But I decided to buy a voice recorder. Which I place in front of lecturer. Which i play back in my spare time. Then I also use soft copies, (Joe 26.01.2017).

In the case of Steel, under the distance-learning mode, where hard copies were given instead of modules in braille format, he had to think of a solution outside the box.
At registration into the university, I was given modules in hardcopy format. I forced myself to just go and buy a printer/scanner whereby when I got home I had to scan the modules and convert them into soft copies. I had to download a pdf editor which was capable of transforming pdf files to word files. That is what I did with those modules, (Steel 20.01.2017).

Just like Joe and Steel above, Tom and Charm all felt competent enough in the use of computers for academic activities. For Tom, his desktop computer and laptop are well fitted with jaws to aid him when researching, typing and writing on-screen records. In addition, Tom acknowledged the elevator facility fitted within the school of education, which makes movement easy when rushing for lectures. 'Yes, this is our lift. At least this one speaks and has braille. Which makes it very friendly. This is what we refer to as universal design.' For Tau and Bri and Frey, they all had special eye glasses put on during class time as well as during Focused Group Discussion. The eyeglasses aided them to see since the three had low vision. As for Charm, Tom, Steel and Joe, they had white cans aiding them navigate their way to learning spaces and around the university. It is clear that the use of white cans, eyeglasses, computers, jaws software, elevator, voice recorder and even the old typewriter helped SwVI successfully learn and progress in their academic endeavours.

Use of technology enabled SwVI to progression and success at Sim University. As reported by the seven participants, they all appeared to be using jaws supported technology to access information especially the blind students. For the low sighted, they all used computers with magnifying tools to enlarge the content. The use of ALD phenomenon reported above is consistent with Thurston's (2014) observation in the use of technology in schools. He observes that increasingly, technology is applied by SwVI to provide curriculum access. Conversely, several studies take a view that technology promotes learning without considering the social implications of development and how technology may affect them (Alves, Monteiro, Rabello, Gasparetto and Carvalho, 2009).

\section{CONCLUSION}

In conclusion, SwVI are faced with a host of disablers on a daily basis to progress through their academic journey at higher education level. Whereas resources are limited in universities similar to Sim University, SwVI carry with them unexploited resources that administrators, managers and teaching staff can tap into and devise innovative ways to combat exclusion. To this effect, ICTs solutions applications make sense when implemented in consultation with SwVI. If only they can be engaged and consulted in decision-making process, institutions are bound to make break-through to a multitude of inclusive education related challenges encountered using ICTs in institutions of higher learning. 


\section{Recommendations}

Based on the findings of the current study, the researchers recommend the following:

i). Involve SwVI in ICT selection and deployment decision-making process affecting their academic progression.

ii). Provide access to suitable technology. Such tools could include white cans, talking watches, voice recorders, embossers and elevators.

iii). Empower teaching staff with ICT skills related to the education of SwVI to be able to implement inclusive education.

\section{REFERENCES}

[1] I.M. Healy. (2012). "Rethinking postnatal care: A Heideggerian hermeneutic phenomenological study of postnatal care in Ireland." [On-line]. PhD Thesis, University of Central Lancashire, Lancashire. Available:

http://clok.uclan.ac.uk/6654/1/Healy\%20Maria\%20Final\%20eThesis\%20\%28Master\%20Copy\%29.pdf. [Feb. 6, 2017].

[2] WHO. (2011). "World Health Report on Disability. Geneva, Switzerland." [On-line]. pp. 8. Available:

http://www.who.int/disabilities/world_report/2011/accessible_e n.pdf [May 4, 2017].

[3] UNICEF. (2013). "The State of the World's Children." [Online]. New York, USA. Available:

https://www.unicef.org/sowc2013/files/SWCR2013_ENG_Lo_r es_24_Apr_2013.pdf [May 4, 2017].

[4] UNESCO. (2014). "EFA Global Monitoring Report 2013/4", [On-line]. Paris, France. pp. 5. Available: http://unesdoc.unesco.org/images/0022/002256/225654e.pdf [May 4, 2017].

[5] A. Harrison and J. Wolforth. (2012). "Findings from a PanCanadian survey of disability services providers in postsecondary education." International Journal of Disability, Community \& Rehabilitation, [On-line]. vol.11, (1). Available: http://www.ijdcr.ca/VOL11_01/articles/harrison.shtml. [Mar. 10, 2017].

[6] G. MacKean. (2011). "Mental health and well-being in postsecondary education settings: A literature and environmental scan to support planning and action in Canada." Canadian Association of College and University Student Success. Available:

http://www.tgao.ca/assets/pdfs/CACUSS.MHCCSudent-MentalHealth-Ju19.2.pdf [Mar. 10, 2017].

[7] C. S. Fichten, V. Ferraro, J.V. Asuncion, C. Chwojka, M. Barile, M.N. Nguyen, R. Klomp, and J. Wolforth, (2009). "Disabilities and e-Learning Problems and Solutions: An Exploratory Study." Educational Technology \& Society, [On-line]. vol. 12, no. 4, pp. 241-256. Available:

http://www.adaptech.org/sites/default/files/abDisabilitiesAndELearningProblems.pdf. [Mar. 10, 2017].

[8] J. Klemes, A. Epstein, M. Zuker, N. Grinberg, and T. Ilovitch. (2006). "As assistive computerized environment for distance learning students with learning disabilities." The Journal of Open, Distance and e-Learning, [On-line]. vol. 21, no. 1, pp. 19-32. Available: http://www.tandfonline.com/doi/abs/10.1080/026805105004680 62. [Mar. 10, 2017].

[9] S. Polushin. (2015). "Inclusive Andragogy in Distance Education: A Phenomenological Perspective." Masters Dissertation, Athabasca University, Canada. Available: https://dt.athabascau.ca/jspui/handle/10791/65. [Mar. 10, 2017].

[10] H. Lourens.( 2015). "The lived experiences of higher education for students with a visual impairment: A phenomenological study at two universities in the Western Cape, South Africa." PhD Thesis. Available: http://scholar.sun.ac.za/handle/10019.1/96732. [Feb. 9, 2017].

[11] A. Gronlund, N. Lim, and H. Larsson. (2010). "Effective Use of Assistive Technologies for Inclusive Education in Developing Countries: Issues and challenges from two case studies." International Journal of Education and Development using Information and Communication Technology (IJEDICT), [Online]. vol. 6, no. 4, pp.5-26. Available:

http://ijedict.dec.uwi.edu/viewarticle.php?id=1136. [Feb. 9, 2017].

[12] D. Langdridge. (2007). Phenomenological psychology: Theory, Research and Methods. [On-line]. London, Pearson. Available: http://oro.open.ac.uk/8332/[Feb. 9, 2017].

[13] M. van Manen. (2007). "Phenomenology of practice." Phenomenology \& Practice, [On-line]. vol. 1, no. 1, 11. Available: http://www.maxvanmanen.com/files/2011/04/2007Phenomenology-of-Practice.pdf. [February 9, 2017]

[14] W.L. Neuman. (2003). "Social Research Methods: Qualitative and Quantitative Approaches" (5 ${ }^{\text {th }}$ ed.). [On-line]. Boston, Allyn and Bacon. Available:

https://www.ajol.info/index.php/ejesc/article/viewFile/65384/53 078. [Feb. 12, 2017].

[15] V. Clarke and V. Braun. (2013). "Teaching thematic analysis: Over-coming challenges and developing strategies for effective learning." The Psychologist, [On-line]. vol. 26, no. 2, pp. 120123. Available: http://eprints.uwe.ac.uk/21155. [June 12, 2017].

[16] E.G. Guba. (1981). "Criteria for assessing the trustworthiness of naturalistic inquiries." Educational Communication and Technology Journal. [On-line]. vol. 29, pp.75-91. Available: https://pdfs.semanticscholar.org/8d32/23ed3c76cc4066ec894b5a ca51c4f4028b7e.pdf. [June 1, 2017].

[17] L. Cohen, L. Manion and K. Morrison. (2000). "Research Methods in Education" (5th ed.). [On-line]. London: Routledge. Available:

https://www.uc.pt/fmuc/gabineteeducacaomedica/recursoseduca re/livro35. [June 1, 2017].

[18] M. Thurston. (2014). "They Think They Know What's Best for Me": An Interpretative Phenomenological Analysis of the Experience of Inclusion and Support in High School for Visionimpaired Students with Albinism." International Journal of Disability, Development and Education. [On-line]. vol. 61, no. 2, pp.108-118. Available:

http://dx.doi.org/10.1080/1034912X.2014.905054. [June 1, 2017].

[19] C. C. F. Alves, G.B.M. Monteiro, S. Rabello, M. E. R. F. Gasparetto and K.M. Carvalho. (2009). "Assistive technology applied to education of students with visual impairment." Revista Panamericana de Salud Pública, [On-line]. vol. 26, pp. $148-152$. 